\title{
The relationship of some administrative variables and the general evaluation of small projects: A case study at Mallawi center, Minya governorate, Egypt
}

\author{
El-Reedy G. H., Ali M. A." \\ Agricultural Economic Department, Faculty of Agriculture, Minia university, Minia, Egypt
}

\begin{abstract}
The study aimed to identify the evaluation and the nature of the relationship between administrative variables and the degree of general evaluation of the project. The study was conducted at Mallawi Center, Minya Governorate, for those who obtained loans from banks to make projects, and my father numbered (220) singles, and the descriptive analytical approach and case study method were used. The most important results to The relationship between evaluation and preparation of a feasibility study, management and experience and the number of years of experience have been demonstrated. The study recommended the importance of evaluation. The results indicated that:

1- That $85 \%$ of the respondents use employment in their projects, and that $15 \%$ depend on themselves only.

2- The higher percentage of respondents assert that they had experience in their projects before borrowing from banks, as the percentage of those with experience in their projects reached $85.5 \%$, and only $14.5 \%$ did not have experience in their projects.

3- That $29.3 \%$ of the respondents have technical expertise in the field of their projects, and that $52.6 \%$ of the owners of the projects have commercial experience, which is most of the projects. As for administrative experience, it was only $18.1 \%$.

4- The relationship between the degree of general evaluation of the project and the employment of workers in the project works was proved to be significant at 0.05 , where the value of the correlation coefficient was 0.176 .

5- Demonstration of the significance of the relationship between the overall evaluation of the project. A feasibility study was prepared, at the level of significance 0.01 , where the value of the correlation coefficient was 0.370 . The relationship between the general evaluation score of the project and the project management, experience, and the number of years of experience was established at the level of significance 0.05 , where the value of the correlation coefficient $0.194,0.188,0.150$.
\end{abstract}

Keywords: evaluation, administrative variables, small projects.

*Corresponding author: Ali M. A., 


\section{Introduction}

Many countries depend on small and micro projects as a main hub for development in increasing production and providing services. Therefore, most countries are keen to work on increasing the success of small and micro projects by taking many measures and means and developing plans, educational curricula and training programs that qualify young men to become men. Business. In addition to providing facilities and advantages for small and micro projects. In order to be able to identify the extent of projects success, these projects must be evaluated by identifying the extent of benefiting from them as well as their importance for the people of villages to which the projects are located. It is the evaluation of these projects. (Human, 1990). As for evaluation, it is an activity that we practice on a daily basis, because we always make judgments about the value of the things we do or do. Taylor knows that it is the process of determining the value of something. Boyle is known to measure the degree of mastery of what we are trying to accomplish. Valuation means determining the feasibility or usefulness of the project, meaning that it will benefit in its establishment and operation? How much is that feasibility or expected benefit?.

Evaluation concepts: (Al-Banna, 2011). Evaluation is the issuance of judgments about a program or project based on specific criteria. It is also known as the use of scientific methods to collect, analyze, and use information to answer basic questions about the project, and to ensure that these answers are supported. In evidence, evaluation is the process of determining project value and effectiveness, and it uses assessment and efficacy tools to provide evaluation data. Estimation is the measurement of the practical results of a particular activity, such as training, and its results in the work environment, while effectiveness determines whether the purposes of the training have been met.

Types of Evaluation (Muharram and ElShazly, 2008):

1- External evaluation: It is carried out by a person who is not involved in the work of the program or project, and therefore he has nothing to gain or lose from evaluation, which makes him unbiased, and more objective in the evaluation.

2- Internal evaluation: It is carried out by a person who works mainly in the program or project, and therefore he knows the program well in terms of strengths and weaknesses, or the problems he faces, and then it is difficult for this person to carry out the evaluation process impartially because it may be affected by his personal opinions, or His relationships with others.

The Objective of the Evaluation: It is to help the specialists and the owners of the projects to determine whether the project succeeded or failed to achieve its objectives. If it had failed, what are the factors that prevented its success? The evaluation also aims to enable specialists and project owners to make the necessary adjustments to increase the project's 
capacity and effectiveness while improving its performance level. The evaluation also aims to examine the project components from the economic side related to income-generating activities, as well as the development side to support the activities of project development centers that aim to improve the capabilities, skills and information of project owners with a view to raising their awareness of their social and economic jobs.

Components of project evaluation (Barakat et al., 2002):

1- Technical evaluation of projects: The purpose of the technical evaluation is to identify technical problems related to construction, civil works, equipment and equipment, their forms and types, as well as problems related to production and operation requirements, in addition to factors related to the site and the requirements and resources required and commissioned, and the availability of production requirements in local markets and various offers thereof.

2- Administrative evaluation of projects: It begins with setting the first visualization of the organizational structure of the project in various administrative and technical cadres, and the evaluation includes identifying:

A. The efficient administrative and technical cuadar in its various levels, the technical workforce in its various forms and its availability.
B. Arranging jobs, classifying and describing them, and wage and incentive policies.

C. Laying out the functional structure with identifying the different activities, divisions, and relations between all elements.

D. Determination of objective moments in evaluating the work of workers and avoiding personal and subjective factors.

E. Establishing programs to train and develop competence for all project workers, in light of the rapid development of various technologies and the necessity to follow in terms of how to manage, operate and maintain these advanced technologies.

F. Establishing programs to train and develop competence for all project workers, in light of the rapid development of various technologies and the necessity to follow in terms of how to manage, operate and maintain these advanced technologies.

G. Determining the method of making decisions and adopting technical methods and scientific tools that are relied upon in this regard.

3- Financial or commercial evaluation of the project: The financial or commercial evaluation of projects is concerned with measuring the financial or commercial profits of these projects from the point of view of the individuals who own those projects and their participants. Financial or commercial evaluation of projects is limited to identifying the external and internal expenditures of these projects, estimating their 
quantities and assessing their value on direct or internal direct and internal flows only.

4- The economic evaluation of women legislators: The economic evaluation of projects is concerned with measuring the economic profitability of these projects from the point of view of society as a whole and not from the point of view of individuals as in the financial evaluation. Kharga and indirect or secondary entrances, such as the impact of the project on the production and related sectors, i.e. the front and back links of the project.

5- Social evaluation of projects: The evaluation from the point of view of the social system is a continuous and continuous work concerned with analyzing the effects of the various projects and their effects on the social entity, and a tool for identifying the social problems created by the projects, and for the purpose of benefiting from the lessons learned to improve the performance of existing projects and adopting a constructive approach in any work required in the future.

The Study Problem: It is clear to us from the previous presentation that the general evaluation of the project has to do with dealing with the owners of the projects and its relationship with government institutions and therefore we had to expose the relationship of individuals to the general evaluation of the project and its impact on individuals. So the problem of the study was whether there were variables affected in the evaluation.

The study problem can be presented in answering the following questions: What is the nature of the relationship between the administrative variables and the general evaluation of the project?

Objectives of the Study: By presenting the study problem, the study aims to:

1- Knowing the degree of evaluation

2- Knowing the administrative variables that affect the general evaluation of the project.

3- Explain the relationship between some the administrative variables and the general evaluation of the project.

Assumptions of the Study: There is no relationship between the following administrative variables: (project management, preparation of a feasibility study for the project, experience in the project field, type of experience, number of years of experience), and the degree of general evaluation.

\section{Materials and methods}

Geographical scope: Mallawi Center in Minya Governorate, Egypt. The human field: It refers to the individuals to whom the field study was applied, and in this study all those who obtained loans were done to start small projects. Time domain: means the time period during which field data was collected, as field data was collected in the period from April to May 2017. 


\subsection{Sample selection method}

All the recipients of the loans are listed in the center.

\subsection{Type of study and curriculum used}

This study is considered a group of descriptive and analytical studies because it was based on describing the study community and analytical by selecting causal hypotheses related to the general evaluation of projects and it depends on the survey method Comprehensive through structured or semi-structured interviews on the study population. It also depends on the case study methodology as it is studying the Mallawi Center in Minya governorate, Egypt.

\subsection{Data collection tools}

The study relied on gathering the necessary data for it on the personal interview of the respondents with the application of the questionnaire form that was designed for that to measure the research variables. The questionnaire was initially tested on 20 subjects from the Dermawas Center to ensure the validity of the questions and the respondents' understanding of them to obtain the required responses with accuracy, and the required adjustments were made. The form was designed in its final form.

\subsection{Statistical analysis tools}

In light of the objectives of the study, as well as the nature of the data (qualitative - quantitative) and the level of measurement of the variables under study (nominal - orderly - inferential - relative), some descriptive statistical tools (percentages, repetitions, etc.) were used to describe the demographic, social, economic and administrative variables in those studying. The "person correlation" coefficient was also used in the case of the variables that were measured by a yardstick (quantitative) to determine the nature of the relationship between the independent variables of the subjects and the studied dependent variables as well as multiple regression.

\subsection{Study variables and procedural definitions and how to measure them}

This section deals with the procedural definitions of study variables and how they are measured by the form as follows.

\subsubsection{First: The dependent variable}

The degree of general evaluation of the project: This variable means the degree to which the success of the project is determined by its importance and the best satisfaction of the borrower. This variable has been measured by the following axes: Degree of benefit from the project: It is intended to know whether the individual benefits from the establishment of the project, whether material or moral. This variable was measured by the use of a three-degree scale: large benefit, to some extent, did not benefit, and the following weights were given responses $3,2,1$. The degree of importance of the project to the people of the village: It refers to the return to the 
village and the importance of the project to the village and the people. This variable was measured through the use of a scale consisting of three degrees: they are of great importance, to some extent, not important, and the responses were given the following weights $3,2,1$. Degree of project success: It means the degree to which an individual feels the success of his project. This variable was measured by using a scale of three degrees: very good, successful, good, poor success, and responses were given the following weights $3,2,1$. The study considered the total sum of the previous four axis grades as an indicator of the overall evaluation of the project. The overall range of the indicator ranged between (12-4) where the weak degree (6: 4) represents the degree, and the average degree (9: 7) represents the degree, The high score represents a high (12:10) degree.

\subsubsection{Second: Independent variables and their methods of measurement}

Administrative variables: include in this study. Manage the project by itself: This variable was measured based on the respondent's question about his management of the project or the management of others. Preparing a feasibility study: This variable was measured based on whether or not the respondent asked about the feasibility study of the project. Experience in the project field: This variable was measured based on the respondent's question about his experience in the project field. Type of experience: This variable was measured based on the respondent's question on the type of technical, commercial, managerial or financial expertise. Years of Experience: This variable was measured based on the researcher's question about the number of years of his experience in the project field.

\section{Results and Discussion}

\subsection{First: with regard to the evaluation of projects}

\subsubsection{The importance of the project in relation to the village}

Table (1) data shows that most of the respondents assert that their projects have great importance for the village in which the project works, as the rate of great importance was (78.2\%), and all respondents emphasized that there is no project that has no importance for the village.

Table (1): Distribution of respondents according to the importance of the project.

\begin{tabular}{clccc}
\hline No. & The importance of the project to the village & Number & $\%$ \\
\hline 1 & very important & 172 & 78.2 \\
\hline 2 & To some extent & 48 & 21.8 \\
\hline 3 & Not important & - & - \\
\hline & Total & 220 & 100 \\
\hline
\end{tabular}




\subsubsection{The degree of benefit from the project}

The results recorded in Table No. (2) showed that $59.1 \%$ confirmed that there is benefit from projects in a very reasonable degree, and that only $4.5 \%$ did not benefit from their project.

\subsubsection{Project evaluation}

The results recorded in Table (3) showed that the degree of success of projects is very high, as the data indicated that
$69.1 \%$ of the projects' success rate is a very good percentage.

\subsubsection{Evaluating success in the legitimate business world}

The results recorded in Table No. (4) showed that the success rate of projects is very high, as the data proved that successful projects with a very good degree were $13.2 \%$, and the degree of success is good at $75.9 \%$, and this is a very high percentage, which confirms the success of the projects.

Table (2): Distribution of the sample population according to the degree of benefit.

\begin{tabular}{clll}
\hline No. & Degree of benefit & Number & $\%$ \\
\hline 1 & Great benefit & 80 & 36.4 \\
\hline 2 & To some extent & 130 & 59.1 \\
\hline 3 & Not benefit & 10 & 4.5 \\
\hline & Total & 220 & 100 \\
\hline
\end{tabular}

Source of the study sample

Table (3): Distribution of the sample population according to the degree of evaluation.

\begin{tabular}{clcc}
\hline No. & Degree of evaluation & Number & $\%$ \\
\hline 1 & Very successful & 55 & 25.0 \\
\hline 2 & To some extent & 152 & 69.1 \\
\hline 3 & Not successful & 13 & 5.9 \\
\hline & Total & 220 & 100 \\
\hline
\end{tabular}

Source of the study sample

Table (4): Distribution of respondents according to the degree of success.

\begin{tabular}{clcc}
\hline No. & Degree of evaluation & Number & $\%$ \\
\hline 1 & Very good & 29 & 13.2 \\
\hline 2 & Good & 167 & 75.9 \\
\hline 3 & Weak & 24 & 10.9 \\
\hline & Total & 220 & 100 \\
\hline
\end{tabular}

Source of the study sample

\subsection{Second: With regard to was borrowed}

administrative variables

\subsubsection{Managing the project for which it $93.2 \%$ of the respondents are the owner}

The results in Table No. (5) showed that 
and owner of the project, and only $6.8 \%$ manage and not the project owner.

Table (5): Distribution of sample personnel according to the project management.

\begin{tabular}{clcc}
\hline No. & Project management & Number & $\%$ \\
\hline 1 & Owner & 205 & 93.2 \\
\hline 2 & Only director & 15 & 6.8 \\
\hline & Total & 220 & 100 \\
\hline
\end{tabular}

Source of the study sample

\subsubsection{Conducting a feasibility study for the project}

The results recorded in Table No. (6) showed that $68.2 \%$ of the respondents had conducted feasibility studies in the field of their projects, and that only $31.8 \%$ did not conduct feasibility studies, which confirms the success of the projects.

\subsubsection{Experience in the field of the project for which it was borrowed}

The results recorded in Table No. (7) showed that the highest percentage of respondents confirm that they had experience in their projects before borrowing from banks, as the percentage of those with experience in their projects reached $85.5 \%$, and only $14.5 \%$ did not have experience in their project.

\subsubsection{Type of experience}

It is clear from the data of Table No. (8) that (29.3) of the respondents have technical experience in the field of their projects and that $(52.6 \%)$ of the owners of projects have commercial experience, which is most of the projects. As for administrative experience, it was $18.1 \%$.

\subsubsection{Years of experience}

It is clear from the data of Table No. (9) that the number of years of experience has a great importance in the projects, and the data indicated that $43.1 \%$ of the respondents have five to ten years of experience, and (30.3\%) more than ten years.

Table (6): Distribution of sample individuals according to a feasibility study.

\begin{tabular}{clcc}
\hline No. & Feasibility study & Number & $\%$ \\
\hline 1 & A feasibility study has been prepared & 150 & 68.2 \\
\hline 2 & No feasibility study has been done & 70 & 31.8 \\
\hline & Total & 220 & 100 \\
\hline
\end{tabular}

Source of the study sample

Table (7): Distribution of the sample personnel according to the experience in the project.

\begin{tabular}{llcc}
\hline No. & The experience & Number & $\%$ \\
\hline 1 & There is experience & 188 & 85.5 \\
\hline 2 & There is no & 32 & 14.5 \\
\hline & Total & 220 & 100 \\
\hline Source of the study sample
\end{tabular}

Source of the study sample 
Table (8): Distribution of sample individuals according to the type of experience.

\begin{tabular}{clcc}
\hline No. & Type of experience & Number & $\%$ \\
\hline 1 & Less than five years & 55 & 29.3 \\
\hline 2 & $(5-10)$ years & 99 & 52.6 \\
\hline 3 & More than 10 years & 34 & 18.1 \\
\hline$\quad$ Total & 188 & 100 \\
\hline Source of the study sample & &
\end{tabular}

Table (9): Distribution of sample individuals according to the number of years of experience.

\begin{tabular}{llcc}
\hline No. & Duration of experience & Number & $\%$ \\
\hline 1 & There is experience & 50 & 26.6 \\
\hline 2 & There is no & 81 & 43.1 \\
\hline 3 & Management experience & 57 & 30.3 \\
\hline & Total & 188 & 100 \\
\hline
\end{tabular}

Source of the study sample

3.3 Third: with regard to testing the significance of statistical assumptions

\subsubsection{The relationship between the overall evaluation of the project and the administrative variables}

To test the significance of the relationship between the overall evaluation of the project and the administrative variables separately, were used the simple correlation coefficient was used for
Pearson. The results of Table No. (10) indicated the significance of the relationship between the overall evaluation of the project. Significant level of 0.01 where the correlation coefficient value was (0.370). The relationship between the general evaluation score of the project and the project management, experience, and the number of years of experience was established at the level of significance 0.05 , where the value of the correlation coefficient $(0.194,0.188$, $0.150)$.

Table (9): Distribution of sample individuals according to the number of years of experience.

\begin{tabular}{llcc}
\hline No. & Duration of experience & Number & $\%$ \\
\hline 1 & Project management & $0.194^{*}$ & 0.05 \\
\hline 2 & Preparing a feasibility study & $0.370^{* *}$ & 0.01 \\
\hline 3 & Experience & $0.188^{*}$ & 0.05 \\
\hline 4 & Type of experience & 0.069 & -- \\
\hline 5 & Years of Experience & $0.150^{*}$ & 0.05 \\
\hline Source of the study sample. F= 9.959, R2 $=0.189$. & &
\end{tabular}

As for the relationship between the overall evaluation of the project and the administrative variables combined and by testing the relationship significance, the multiple regression model was used, where the significance of the model was established at the level of significance 0.01 where the calculated value of $(\mathrm{P})$ 
was 9.959. The coefficient of determination indicated that the administrative variables explain 18\% of the total variance in the dependent variable, which is the degree of the overall evaluation of the project, where the value of the coefficient of determination was 0.189. Based on the results of the study, the following can be recommended:

1- Interest in spreading awareness of choosing projects of interest to villages.

2- It should be noted that there are offices to study feasibility and help young people, and that these offices be in local units.

3- The project owners are aware of the importance of evaluation at all stages of the project and during the project's work.

\section{References}

Al Banna, M. (2011), Evaluation of scientific foundations projects and practical applications, Faculty of Economics and Management, King Abdul-Aziz University, Saudi Arabia, pp. 12.

Barakat, M. M., Abdel-Aziz, Sh. and ElShazly, S. S. (2002), Evaluation of rural social projects, Faculty of Agriculture, Ain Shams University, Cairo, Egypt, pp. 72.
Muharram, I. S. and El-Shazly, S. S. (2008), Evaluation of rural social projects, Faculty of Agriculture, Ain Shams University, pp. 10.

Human Development report (H.D.R). (1990), University Leadership Development Programme New York, USA, pp. 2009. 